\title{
$\mathrm{PH} 100_{\text {debate }}$
}

a debate Repositorios y redes sociales académicas para la transferencia del conocimiento abierto

| coordina Remedios Melero Melero

\section{Retos de la difusión de la investigación en acceso abierto}

Rocío Serrano Vicente | Servicio de Bibliotecas, Universidad de Navarra

URL de la contribución <www.iaph.es/revistaph/index.php/revistaph/article/view/4671>

La comunicación académica ha cambiado en los últimos años. Los investigadores pueden difundir su investigación en muchas plataformas, ya sean solo académicas o de otro tipo (Twitter, Facebook, por ejemplo). En este debate se han enumerado las ventajas que ofrecen las redes sociales académicas (como Academia.edu o ResearchGate) en comparación con los repositorios institucionales (vía verde) o revistas de acceso abierto (vía dorada).

Efectivamente, las plataformas académicas se usan con más facilidad, envían correos para actualizar los perfiles de usuarios, y ponen en contacto con otros profesionales que estudien en el campo del investigador. Gracias a la profesionalidad de los gestores de repositorios y la ayuda de organismos oficiales, se ha conseguido el reto de facilitar al máximo la introducción de publicaciones en esos repositorios institucionales y la comprobación de las políticas editoriales.

Las mejoras tecnológicas están orientadas a la interoperabilidad de las herramientas que manejan los investigadores, con el fin de que no haya que introducir los datos en muchas plataformas, y de que, de una sola vez, sus publicaciones estén disponibles en los CRIS de las instituciones, el repositorio, etc.

En 2016, se realizó una encuesta al personal investigador de la universidad de Navarra, intentando averiguar su conocimiento del acceso abierto, y si lo ponían en práctica. Otras cuestiones que se planteaban eran las motivaciones que animaban a difundir sus trabajos en acceso abierto, y de qué modo (repositorios, redes sociales académicas, etc.). Los resultados de esta encuesta (SERRANO-VICENTE; MELERO; ABADAL, 2016) aportan resultados interesantes, porque se concluyó que varios factores influían en la adopción del acceso abierto.
Así, se dedujo del estudio de la encuesta que la decisión de publicar en revistas de acceso abierto o de depositar sus trabajos en repositorios está directamente relacionada con la recompensa académica y el reconocimiento profesional. Como ya se ha dicho en otras contribuciones de este debate, el mandato o recomendación por parte de la institución para difundir las publicaciones en abierto es un punto de partida para fomentar la vía verde, pero lo definitivo sería que tuviera un reflejo en los sistemas de evaluaciones. Como indica Alexandre López Borrull (pp. 105-107), el que las publicaciones aparezcan en los perfiles de Google Scholar, que recogen también el número de citas, puede ser un elemento que convenza al investigador. En este aspecto es fundamental el alinear la política del repositorio institucional con la política de la institución. Siempre es posible encontrar en los objetivos de cada institución algún punto que favorezca la difusión de la investigación de la institución y, en ese aspecto, se puede trabajar con los gestores de investigación. Cualquier iniciativa que favorezca el desarrollo profesional de los investigadores será muy bien acogida. Y hará que merezca la pena el esfuerzo necesario para que sus publicaciones estén en el repositorio institucional.

Otros dos factores clave que influían en la participación en el repositorio institucional eran los diferentes modelos de comunicación académica de acuerdo con las áreas de conocimiento y la edad de los investigadores.

Se agruparon en bloques de áreas temáticas para estudiar en qué plataformas se difundían las publicaciones en acceso abierto. En Ingeniería, Ciencias Exactas y Física, debido a que tienen experiencia en la difusión a través de repositorios de acceso abierto, se observa que se utilizan con más frecuencia el repositorio y en segundo lugar las revistas de acceso abierto. En el área de Ciencias de la Salud, existen revistas en acceso abierto que tienen alto factor de impacto. Pero también 


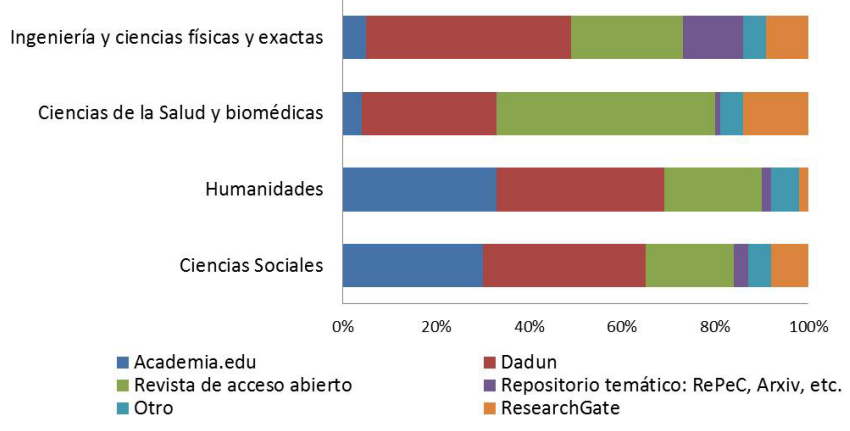

Publicación en acceso abierto según la disciplina de los encuestados (U. de Navarra) (SERRANO-VICENTE; MELERO; ABADAL, 2016)

publican en revistas con APC, ya que lo que les interesa es que tenga factor de impacto y que se difunda cuanto antes. En el caso de la Universidad de Navarra, los perfiles de Humanidades y Ciencias Sociales han conocido el acceso abierto a través del repositorio institucional y no tienen tantas revistas de alto factor de impacto. Por este motivo su inclusión de artículos en el repositorio les asegura la difusión a través de Internet, aunque también están presentes en redes sociales académicas tipo Academia.edu.

La edad también influye en la voluntad de depositar la producción científica en el repositorio. En el grupo de mayor edad, la responsabilidad de difundir la investigación en acceso abierto fue la razón más citada para introducir documentos en DADUN. También hay que tener en cuenta que ya tienen una carrera académica consolidada y no están preocupados por el plagio. Los investigadores de edad intermedia depositan porque han recibido un mandato de las autoridades académicas, y los jóvenes, para difundir su investigación fuera de la universidad. Sin embargo, estos últimos son los que están más preocupados por infringir los derechos de copyright o por el plagio. Es llamativo que la mayoría de investigadores, en todos los grupos de edades, no encontraron ninguna ventaja en introducir los documentos en el repositorio institucional.

El investigador se encuentra ante un panorama complicado para difundir la investigación. Se les aconseja que estén en distintas plataformas: ORCID, ResearcherID, ScopusID, repositorio institucional. Además, deben introducir sus datos en el CRIS, en las plataformas de la ANECA, para su evaluación y desarrollo profesional. Piensan que el tiempo que dedican a estas tareas es inútil, porque cada plataforma es distinta, y deben introducir los datos siguiendo un sistema diferente. Y, lo más importante, creen que deben dedicar su tiempo a investigar y otras tareas académicas, no a trabajos administrativos. Por tanto, cuando encuentran una herramienta que les facilita al máximo la introducción de su investigación, les alerta cuando se introduce en la plataforma una nueva publicación para comprobar si es suya, les permite introducir el artículo y relacionarse con sus colegas, conociendo inmediatamente sus nuevas investigaciones, no es extraño que vean este sistema como su salvación. Es claro que no piensan en el copyright de las revistas, ni en que son plataformas de pago, que tarde o temprano les cobrarán por su presencia en esas redes.

En mi opinión la presencia en redes sociales académicas y el repositorio pueden ser compatibles, especialmente si se consigue, como indica Amparo Cózar en este mismo debate (pp. 95-97), que se incluya en las redes el enlace al documento en el repositorio. Sin embargo, todavía creo que hace falta una integración mayor entre todas las plataformas para que el investigador introduzca una sola vez los datos de investigación y puedan exportarse automáticamente a todas las plataformas. El compromiso de la institución y de las agencias evaluadoras es necesario para que se premie la difusión en acceso abierto.

\section{BIBLIOGRAFÍA}

- SERRANO-VICENTE, R.; MELERO, R.; ABADAL, E. (2016) Open Access Awareness and Perceptions in an Institutional Landscape. Journal of Academic Librarianship, vol. 42, n. ${ }^{\circ}$ 5, 2016, pp. 595-603 <https://doi.org/10.1016/j. acalib.2016.07.002> [Consulta: 12/05/2020] 